\title{
Spatial Properties and Functional Organization of Small Bistratified Ganglion Cells in Primate Retina
}

\author{
Greg D. Field, ${ }^{1 *}$ Alexander Sher, ${ }^{2 *}$ Jeffrey L. Gauthier, ${ }^{1 *}$ Martin Greschner, ${ }^{1}$ Jonathon Shlens, ${ }^{1}$ Alan M. Litke, ${ }^{2}$ and \\ E. J. Chichilnisky ${ }^{1}$ \\ ${ }^{1}$ Salk Institute for Biological Studies, La Jolla, California 92037, and 2Santa Cruz Institute for Particle Physics, University of California, Santa Cruz, California \\ 95064
}

The primate visual system consists of parallel pathways initiated by distinct cell types in the retina that encode different features of the visual scene. Small bistratified cells (SBCs), which form a major projection to the thalamus, exhibit blue-ON/yellow-OFF [S-ON/(L+M)OFF] light responses thought to be important for high-acuity color vision. However, the spatial processing properties of individual SBCs and their spatial arrangement across the visual field are poorly understood. The present study of peripheral primate retina reveals that contrary to previous suggestions, SBCs exhibit center-surround spatial structure, with the (L+M)-OFF component of the receptive field $\sim 50 \%$ larger in diameter than the S-ON component. Analysis of response kinetics shows that the (L+M)-OFF response in SBCs is slower than the S-ON response and significantly less transient than that of simultaneously recorded OFF-parasol cells. The (L+M)-OFF response in SBCs was eliminated by bath application of the metabotropic glutamate receptor agonist L-APB. These observations indicate that the $(\mathrm{L}+\mathrm{M})$-OFF response of SBCs is not formed by OFF-bipolar cell input as has been suspected and suggest that it arises from horizontal cell feedback. Finally, the receptive fields of SBCs form orderly mosaics, with overlap and regularity similar to those of ON-parasol cells. Thus, despite their distinctive morphology and chromatic properties, SBCs exhibit two features of other retinal ganglion cell types: centersurround antagonism and regular mosaic sampling of visual space.

Key words: receptive field; color; vision; APB; blue-yellow; opponent; nearest neighbor; center-surround; koniocellular; mosaic

\section{Introduction}

A unifying principle of sensory systems is the existence of parallel pathways conveying distinct information from peripheral sensory organs to distinct targets in the brain. In the primate visual system, 17-22 anatomically defined types of retinal ganglion cells (RGCs) project to distinct brain areas (Dacey, 2004; Yamada et al., 2005; Field and Chichilnisky, 2007). One RGC type, the small bistratified cell (SBC), carries chromatic information densely sampled across the visual field (Dacey, 1993a; Dacey and Lee, 1994; Ghosh et al., 1997). SBCs exhibit an excitatory response to increments of absorbed light in the short-wavelength-sensitive (S) cone photoreceptors, and decrements of absorbed light in middle-wavelength-sensitive (M) and long-wavelength-sensitive (L) cones. This generates a signal appropriate for the perception

Received July 29, 2007; revised 0ct. 19, 2007; accepted 0ct. 20, 2007.

This work was supported by the Helen Hay Whitney Foundation (G.D.F.), Burroughs Wellcome Fund Career Award at Scientific Interface (A.S.), National Institutes of Health (NIH) National Research Service Award and Chapman Foundation (J.L.G.), German Academic Exchange Service (M.G.), National Science Foundation (NSF) Integrative Graduate Education and Research Traineeship DGE-033451 (J.S.), McKnight Foundation (A.M.L., E.J.C.), NSF Grant PHY-0417175 (A.M.L.), a Sloan Research Fellowship, and NIH Grant EY017992 (E.J.C). We thank B. Kutka and C. Hulse for technical assistance; M. I. Grivich, D. Petrusca, W. Dabrowski, A. Grillo, P. Grybos, P. Hottowy, and S. Kachiguine for technical development; H. Fox, M. Taffe, E. Callaway, and K. Osborn for providing access to retinas; and S. Barry for machining. We thank the San Diego Supercomputer Center and the NSF (Cooperative Agreements 05253071 and 0438741) for large-scale data storage.

${ }^{*}$ G.D.F., A.S., and J.L.G. contributed equally to this work.

Correspondence should be addressed to Greg D. Field, Systems Neurobiology, The Salk Institute, 10010 North Torrey Pines Road, La Jolla, CA 92037. E-mail: gfield@salk.edu.

DOI:10.1523/JNEUROSCI.3437-07.2007

Copyright $\odot 2007$ Society for Neuroscience $\quad 0270-6474 / 07 / 2713261-12 \$ 15.00 / 0$ of bluish and yellowish hues, a fundamental aspect of color vision (Wandell, 1995; Dacey and Packer, 2003). However, the spatial receptive field properties of SBCs, and their spatial arrangement across the visual field, are largely unknown or controversial.

First, recordings from unidentified blue-yellow opponent neurons (Wiesel and Hubel, 1966; de Monasterio, 1978a,b) suggest that regions of blue-ON and yellow-OFF sensitivity are often spatially coextensive, producing a chromatic signal without the center-surround antagonism classically associated with RGCs (Kuffler, 1953). This receptive field structure could arise from the distinct inner and outer stratifying dendrites of SBCs respectively making contacts with S-ON and ( $\mathrm{L}+\mathrm{M})$-OFF bipolar cells. This proposed circuit differs from the horizontal cell mediated feedback that contributes to center-surround antagonism in other RGC types (Werblin and Dowling, 1969; Mangel, 1991; McMahon et al., 2004). However, blue-yellow opponent cells exhibiting more standard center-surround antagonism have also been observed (Wiesel and Hubel, 1966; de Monasterio, 1978a,b; Derrington and Lennie, 1984). Thus, it remains unclear whether the receptive field structure and the underlying circuitry of SBCs are similar to those of other RGC types.

Second, the collective spatial sampling properties of SBCs have not been investigated. Morphological and physiological studies in several species suggest that each RGC type constitutes a complete visual representation, with dendritic and receptive fields forming uniform mosaics that tile visual space (Wassle et al., 1981; Dacey, 1993b; DeVries and Baylor, 1997; Chichilnisky 
and Kalmar, 2002; Frechette et al., 2005). However, recent findings in salamander retina suggest that functional mosaic organization may be a property of only certain RGC types (Segev et al., 2006). Thus, determining the ensemble spatial arrangement of SBC receptive fields will reveal fundamental properties of a major chromatic pathway in the primate visual system and provide a test of the generality of mosaic organization.

This study exploits a large-scale multielectrode recording system (Litke et al., 2004; Frechette et al., 2005) to reveal the spatial receptive field and ensemble sampling properties of SBCs in peripheral primate retina (25-70 deg). Despite distinct chromatic properties and morphology, SBCs resemble other RGC types in two major respects: center-surround antagonism and mosaic sampling of the visual scene.

\section{Materials and Methods}

Preparation and recording methods were described previously (Chichilnisky and Kalmar, 2002; Litke et al., 2004; Frechette et al., 2005). Eyes were enucleated from terminally anesthetized macaque monkeys ( $\mathrm{Ma}$ caca mulatta) used by other experimenters in accordance with institutional guidelines for the care and use of animals. Some animals, in the course of other experiments, had been infected with SIV (simian immunodeficiency virus), some had received doses of ethanol or MDMA (3,4methylenedioxy- $N$-methylamphetamine), some had received focal injections of a modified rabies virus in the brain, and some were healthy controls. No systematic differences in retinal physiology were observed in the different populations. No animals displayed obvious behavioral visual deficits.

Immediately after enucleation, the anterior portion of the eye and vitreous were removed in room light. The eye cup was placed in a dark, sealed container with bicarbonated Ames' solution (Sigma, St. Louis, $\mathrm{MO})$ at room temperature. In some experiments, the retinas were transported to the laboratory and thus were kept at room temperature for $15-20 \mathrm{~min}$. Retinas were then warmed to $32-34^{\circ} \mathrm{C}, \mathrm{pH} 7.4$, in oxygenated Ames' solution. Recordings were begun only after the retina had dark adapted at this temperature for at least $20 \mathrm{~min}$. Under infrared illumination, segments of peripheral retina $6-15 \mathrm{~mm}(25-70 \mathrm{deg}, \sim 223 \mu \mathrm{m} / \mathrm{deg})$ (Perry and Cowey, 1985; Drasdo and Fowler, 1974) from the fovea and 3-5 $\mathrm{mm}$ in diameter were dissected and isolated from the retinal pigment epithelium. These segments were taken from regions where the retina was strongly attached to the pigment epithelium, to ensure pigment regeneration after enucleation and vitrectomy. The segment of retina was then placed flat, RGC layer down, on a planar array of 512 extracellular microelectrodes covering an area $1800 \mu \mathrm{m} \times 900 \mu \mathrm{m}$. For recording, the retina was kept at $33-35^{\circ} \mathrm{C}$ and was perfused with Ames' solution bubbled with $95 \% \mathrm{O}_{2}$ and $5 \% \mathrm{CO}_{2}$, $\mathrm{pH} 7.4$.

\section{Recording and spike sorting}

Voltage signals on each electrode were bandpass filtered, amplified, digitized $(20 \mathrm{kHz})$, and stored for off-line analysis (Litke et al., 2004). Candidate spikes on each electrode were identified using a threshold equal to four times the SD of the voltage over time. For each threshold crossing, a waveform vector was constructed using voltage values within a time window ( -0.5 to $0.75 \mathrm{~ms}$ ) around the threshold crossing, along with the simultaneous voltage values from six adjacent electrodes. The waveform vectors were represented as points in a five-dimensional space using the first five principal components (PCs) from principal components analysis (PCA) (Jackson, 1991). These points were separated into distinct clusters using a mixture of Gaussians model fitted with expectation maximization (Duda et al., 2001). The initial conditions and number of clusters were determined automatically using an adapted watershed transformation (Castleman, 1996; Roerdink and Meijster, 2001). Resulting clusters were interpreted to represent spike trains from different cells, subject to two conditions: $<10 \%$ contamination (estimated from refractory period violations $0.5-1.0 \mathrm{~ms}$ after a spike) and an average spike rate $\geq 1 \mathrm{~Hz}$. Note that $64 \pm 13 \%(63 \pm 8 \%)$ of SBCs (ON-parasol cells) exhibited estimated contaminations of zero across preparations. For cells with nonzero contamination, the mean of the estimated spike contami- nation was $3.0 \pm 0.4 \%(\mathrm{SD})$ for SBCs and $2.5 \pm 1.0 \%$ for ON-parasol cells.

Most RGCs produced threshold crossing events on multiple electrodes and thus were identified multiple times. To remove these duplicates, candidate neurons were checked for time correlations in a $10 \mathrm{~ms}$ window. If any two candidate neurons exhibited $>25 \%$ of spikes correlated in time, they were considered duplicates, and only the one with the larger number of spikes was kept. The $25 \%$ threshold was used because duplicate neurons often exhibited $<100 \%$ correlation as a consequence of spikes that failed to be identified on one or more electrodes. Mosaic organization was not influenced by the choice of correlation threshold, and the number of cells found was stable when the threshold was varied from 10 to $50 \%$ (supplemental Fig. 1, available at www.jneurosci.org as supplemental material).

\section{Stimuli}

An optically reduced stimulus from a gamma-corrected cathode ray tube computer display (Multiscan E100; Sony, Tokyo, Japan) refreshing at $120 \mathrm{~Hz}$ was focused on the photoreceptor outer segments. Low photopic intensity was achieved by neutral density filters in the light path. The mean photon absorption rate for the $\mathrm{L}, \mathrm{M}$, and $\mathrm{S}$ cones was approximately equal to the rate that would have been caused by a spatially uniform monochromatic light of wavelength $561(530,430) \mathrm{nm}$ and intensity of $4400(4300,2200)$ photons $/ \mu \mathrm{m}^{2} / \mathrm{s}$ or $1630(1590,810)$ photoisomerizations/cone/s $\left(0.37 \mu \mathrm{m}^{2}\right.$ cone collecting area) (Schnapf et al., 1990).

White noise stimulus. A stimulus composed of a lattice of squares, each flickering randomly and independently at either 30 or $120 \mathrm{~Hz}$, was used to characterize the spatiotemporal response properties of recorded RGCs (Chichilnisky, 2001). The sizes of individual squares (henceforth, pixels) varied from 23.2 to $116 \mu \mathrm{m}$ on a side. For comparison, average SBC and parasol cell receptive field diameters varied from 80 to $220 \mu \mathrm{m}$ across preparations. The intensity of each display phosphor at each pixel location varied in a binary manner; i.e., it assumed one of the two specified values on each refresh (see below).

RGB white noise. To study how populations of RGCs sample visual space, a white noise stimulus was used where the intensities of the three display phosphors at each pixel location varied independently of one another (henceforth, RGB white noise). The contrast of this stimulus for each of the three display phosphors was $98 \%$ (SD of modulation divided by mean intensity).

$S$ versus $L+M$ white noise. In some experiments (see Figs. 2-4), an S versus $\mathrm{L}+\mathrm{M}$ cone-isolating stimulus was used (henceforth, $\mathrm{S}$ versus $\mathrm{L}+\mathrm{M}$ white noise). This stimulus modulated $\mathrm{S}$ cone absorptions at each pixel location independently from $\mathrm{L}$ and $\mathrm{M}$ cone absorptions (Estevez and Spekreijse, 1982); L and M cone absorptions were modulated together. Cone spectral sensitivity was taken from Schnapf et al. (1988). Display phosphor emission spectra were measured through the optical elements between the display and the retina with a spectraradiometer (PR-701; Photo Research, Chatsworth, CA). The effective contrast of the stimulus for each cone type was $44 \%$. To estimate the quality of cone isolation, "filter-isolating" stimuli were generated for three sets of glass filters, with spectral properties similar to the spectral sensitivities of the cones (L: Oriel59500 and Schott BG-40; M: Schott VG-9; S: Oriel 59814 and Oriel 59080) (Chichilnisky and Baylor, 1999). The power of transmitted light through each filter set with each filter-isolating stimulus was measured using a calibrated photodiode (UDT Instruments, San Diego CA). Stimuli intended to isolate each filter group yielded photodiode power measurement ratios in excess of 50:1 in the isolated compared with the nulled filter set. This indicates accurate spectral calibration and cone isolation.

\section{$R G C$ receptive field characterization}

The spatial, temporal, and chromatic receptive field properties of the recorded RGCs were characterized using the spike-triggered average (STA) stimulus during white noise presentation (Rieke et al., 1997; Chichilnisky, 2001). The receptive field structure of each SBC was summarized by fitting the STA with a model consisting of the product of a spatial profile and a temporal profile for each chromatic component 
(Chichilnisky and Kalmar, 2002). The temporal profile was a difference of low-pass filters. The spatial profile consisted of two-dimensional Gaussian functions.

The experiments of Figure 2 used an $\mathrm{S}$ versus $\mathrm{L}+\mathrm{M}$ cone-isolating stimulus. One two-dimensional Gaussian function was fitted to the $\mathrm{S}-\mathrm{ON}$ receptive field component and another to the ( $\mathrm{L}+\mathrm{M})$-OFF component. For Figures 5-8, some data were collected with $S$ versus $L+M$ white noise and others were collected with RGB white noise. Analysis of these data were performed by fitting the $S$ cone-isolating component of the receptive field, or the blue display phosphor component, with a twodimensional Gaussian. No systematic differences were observed in the two types of analysis.

The spatial sensitivity profile of each ON-parasol cell receptive field was obtained by fitting the spatial component of the STA with a difference of Gaussians model, because the center could not be chromatically distinguished from the surround. For the $\mathrm{S}$ versus $\mathrm{L}+\mathrm{M}$ stimulus, the $\mathrm{L}+\mathrm{M}$ response component was fitted. For RGB stimuli, the fit was applied to the entire STA. Parasol cell surrounds were relatively weak, so the following procedure was used to robustly estimate the surround amplitude and size. Receptive fields from all ON-parasol cells in a recording were shifted and summed to generate an average STA spatial profile. This average was well described by a fit in which the radius of the surround was twice that of the center. Thus, an initial two-dimensional Gaussian was fitted to the STA of each cell, generating a rough estimate of receptive field center location and size. Then a surround with a radius twice that of the center was introduced, and the fit was reoptimized, while keeping the ratio between surround and center sizes fixed.

The robustness of fits was checked by varying the initial SD of the two-dimensional Gaussian fit over a factor of four. Cells with noisy STAs and unstable fits were excluded. Fit precision was estimated using the following bootstrap method. For each cell, $n$ spikes were sampled with replacement from the original spike train containing $n$ spikes. The STA based on the resampled spikes was fitted as described above. This procedure was repeated 10 times. The SD of the resulting distribution of fit parameters obtained by bootstrapping was used to estimate the SE of the fit parameters. In Figure $2 E$, the displacement between S-ON and $(\mathrm{L}+\mathrm{M})$-OFF components of each receptive field was normalized by the geometric mean of the SE associated with center and surround fits. The square root of the value corresponding to a significance threshold at $p=$ 0.05 or $p=0.001$ from a $\chi^{2}$ distribution with two degrees of freedom was used to draw the confidence regions (circles).

Bias in estimates of receptive field size and shape can be produced by large stimulus pixels. In each preparation, STAs were measured with several pixel sizes in the range $23.2-116 \mu \mathrm{m}$ (mean receptive field diameter varied between 80 and $220 \mu \mathrm{m}$ across preparations). In 24 of 32 preparations, the estimated receptive field size did not vary significantly with pixel size. In the remaining preparations (those with the smallest receptive fields), a bias as large as $15 \%$ was observed using the largest pixels. In these preparations, pixels $58 \mu \mathrm{m}$ or smaller were used for receptive field size estimates.

For all fits, the location of the Gaussian fit midpoint, the SDs along the major and minor axes, and the angle of the major axis were extracted. These parameters defined an ellipse for each cell that represents the 1 SD contour of the Gaussian fit. In figures, receptive field outlines are represented using this contour. In figures and analysis, the size of the receptive field is summarized by the geometric mean of the SDs along the major and minor axes (equivalently, the radius of a circle with an area equal to that of the 1 SD contour).

\section{Cell classification and identification}

The morphological types of recorded cells were determined using a twostep procedure. First, cells were grouped into functional cell classes based on their light response properties. Second, correspondences between functional classes and anatomical types were determined by density and light response properties.

Classification. A typical example of the functional classification obtained from one recording is illustrated in Figure 1. The STA time courses from all cells were represented in a two-dimensional space using PCA. Figure $1 B$ shows the weights of the first two PCs for the cells in this recording. In the scatter plot, each cell is represented by a point with a location that reflects the shape of the STA time course. Points from a few presumed wide-field RGCs were excluded based on their large receptive field sizes (more than twice as large as parasol cells). The PC plot shows five well defined clusters in this recording, each of which was taken to represent a single functional class. Three distinguishing physiological features of each functional class are shown in Figure 1, $A$ and $C-F$ : (1) the STA time courses; (2) the receptive field sizes; and (3) the spike train autocorrelation functions. Although the functional classes were defined using STA time course information, the cells of each class exhibited a striking homogeneity of receptive field sizes and autocorrelation functions. This homogeneity suggests that the clusters corresponded to irreducible functional cell classes.

Parasol cell identification. The classes in Figure 1, $A$ and $C$, were identified as parasol cells as described previously (Chichilnisky and Kalmar, 2002). Briefly, the identification was based on receptive field sizes, contrast gain, and response kinetics compared with published data (Croner and Kaplan, 1995; Dacey et al., 1996; Lee, 1996). In addition, parasol cell density in locally complete regions of the receptive field mosaic was found to be similar to that from anatomical studies (Silveira and Perry, 1991).

Midget cell identification. The functional classes in Figure 1, D and $F$, were identified as ON- and OFF-midget cells by comparison to parasol cell density, receptive field size, and light response kinetics. In the peripheral retina, ON- and OFF-midget cells are the only RGC types with systematically smaller dendritic fields and higher cell density than parasol cells (Dacey, 2004). In recordings with a sufficient number of isolated cells to measure density, midget cell receptive fields were approximately one-half the size of parasol cell receptive fields, and midget cell density was approximately fourfold greater than parasol cell density. In these preparations, midget cells exhibited consistently slower kinetics and more sustained responses, as expected (Lee, 1996). The sparsity of midget cells observed in Figure 1, $D$ and $F$, is likely attributable to poor spike detection efficiency rather than sparse midget cell populations.

$S B C$ identification. All recordings in this paper contained a functional cell class with $\mathrm{S}-\mathrm{ON} /(\mathrm{L}+\mathrm{M})$-OFF responses like that in Figure $1 \mathrm{E}$. These cells were identified as SBCs based on receptive field size, kinetics, and density. Only two anatomical types of RGCs are known to have S-ON/ (L+M)-OFF responses (Dacey et al., 2003): SBCs and large bistratified cells (LBCs). SBC density has been measured only in temporal retina, where parasol cells (ON and OFF together) are approximately three times as dense as SBCs (Silveira and Perry, 1991; Dacey, 1993b). LBCs, on the other hand, are less than half as dense as SBCs (Dacey, 2004), indicating that total parasol density is at least six times the LBC density. In recordings from temporal retina, the mean ratio of parasol cell density to putative SBC density was 2.9 , confirming that these cells were SBCs rather than LBCs. Furthermore, no other known RGC type has this density relationship to parasol cells (Dacey et al., 2003; Dacey, 2004). The extrapolation of SBC identity to the nasal retina was based on homogeneity (low variability and unimodality) of functional properties within and across preparations. This homogeneity was tested by comparing the time courses and receptive field sizes of putative SBCs to those of simultaneously recorded ON-parasol cells. The ratio of the time to peak of putative SBCs to that of ON-parasol cells across preparations was $1.12 \pm$ 0.02 (mean $\pm \mathrm{SD}$ ). The ratio of receptive field sizes across preparations was $1.1 \pm 0.2$. The latter values are consistent with the ratio of dendritic field sizes of SBCs to those of parasol cells (Dacey, 1993a). If the putative SBCs were composed of two distinct cell types (e.g., SBCs and LBCs), a bimodal distribution of one or both functional properties might have been expected. Across all preparations in nasal and temporal retina, the distributions of both the time to peak and receptive field size of putative SBCs relative to those of ON-parasol cells were unimodal. In summary, the homogeneity of receptive field sizes and kinetics suggests that putative SBCs comprised a single cell type, and cell densities in temporal retina establish this type to be small bistratified.

\section{$L-A P B$ experiment}

For the experiment measuring the effect of $\mathrm{L}(+)$-2-amino-4phosphonobutyric acid (L-APB) on SBC receptive fields, three data runs 
were taken, each $15 \mathrm{~min}$ long using an $\mathrm{S}$ versus $\mathrm{L}+\mathrm{M}$ white noise stimulus with a refresh rate of $30 \mathrm{~Hz}$ and a pixel size of $92.8 \mu \mathrm{m}$. The "preAPB" condition was recorded under normal conditions (oxygenated Ames' solution) and was used to identify, characterize, and classify RGCs. The retina was then perfused with oxygenated Ames' solution and $100 \mu \mathrm{M} \mathrm{L}-\mathrm{APB}$ for $20 \mathrm{~min}, 5 \mathrm{~min}$ for the L-APB to wash in and 15 min of recording time. After completion, the "wash" condition began. Five minutes were allowed for the L-APB to wash out, followed by 15 min of data collection.

Neuron definitions from the first run were applied to the subsequent runs as follows. The five PCs derived from spike waveforms in the pre-APB condition were used to reduce the dimensionality of spike waveforms from the subsequent "APB" and "wash" conditions. The mixture of Gaussians model from the pre-APB condition was applied to the subsequent recordings. Because the spike waveforms of some cells changed slightly, causing the cell definition to be contaminated, only neurons that retained $<5 \%$ contamination and that exhibited similar receptive fields before and after L-APB application were analyzed further.

Responses in the presence and absence of L-APB were compared using the spike-triggered sum (STS), which is computed similarly to the STA, except for the absence of normalization by the total number of spikes. The STS was used because it is robust to changes in spontaneous firing rate, a possible effect of L-APB. Spontaneous spikes do not affect the STS, because they are not correlated with the stimulus. Spontaneous spikes do affect the STA amplitude, because they are included in the normalization. For each cell, stimulus pixels with a significant signal in the STS ( $>3$ SDs above noise) were selected, and their time courses were averaged. The averaged time course before application of L-APB was used as a template and compared with the time course averaged across the same pixels during and after application of L-APB. The comparison was performed by computing the inner product of the "pre-APB" time course, expressed as a vector, with the "APB" and "wash" time courses, divided by the inner product of the former with itself. An unchanged time course would produce a normalized inner product value of one. Complete elimination of the light response would produce a value of zero.

\section{Characterization of mosaic regularity and coverage}

Mosaic regularity. Regularity of SBC receptive field spatial sampling was demonstrated by comparing the nearest neighbor distance (NND) distribution of receptive field centers to that expected from a random distribution: $p(r)=2 \pi \lambda r \exp \left(-\lambda \pi r^{2}\right)$, where $r$ is the distance between points and $\lambda$ is the density (Wassle and Riemann, 1978). Quantitative comparison was performed using a one-sample Kolmogorov-Smirnov $(\mathrm{K}-\mathrm{S})$ test of measured NNDs with the analytical function given above.

Conformity ratio. The conformity ratio (CR; mean/SD) of the nearest neighbor distribution has been used extensively in quantifying the regularity of anatomical mosaics (Wassle and Riemann, 1978; Wassle et al., 1981; Young and Vaney, 1991; Dacey, 1993b; Cook, 1996; Massey and Mills, 1996; Haverkamp and Wassle, 2004). To compare the CR of receptive field mosaics with that of anatomical mosaics required an estimator of the CR that was robust to subsampling and edge effects, errors that can lead to a downward bias (Cook, 1996). Therefore, the CR estimate was based on the NNDs of cells in locally complete parts of the observed mosaics, where local completeness was defined as the presence of at least four neighbors around each reference cell. A natural definition of neighbor relationships for any set of points on the plane is Delaunay triangu- lation (Shapiro et al., 1985; Zhan and Troy, 2000). If two neighbors in the Delaunay triangulation of an observed (possibly incomplete) mosaic appeared to have been neighbors in the underlying real mosaic, the cells were considered neighbors. This decision was based on the distance between cells: any neighbors closer than 1.7 times the median NND were identified as true neighbors. This threshold was chosen to reflect the variability of true neighbor distances observed in regions of the mosaic that appeared complete by visual inspection. The above procedure provided CR estimates with low bias (5-10\%) that was constant when complete mosaics were subsampled by as much as $50 \%$. CR estimates generated by the above procedure were also compared with CR estimates based on all cells from mosaics that were $>90 \%$ complete. These two estimates of the CR differed by $<10 \%$, and the difference was not systematic.

Normalized nearest neighbor distribution. RGC coverage is usually defined as the average number of cells sampling any given point in visual space, based on anatomical measurements of dendritic field extent. In the case of receptive fields approximated by Gaussian fits, the extent is illdefined. To analyze receptive field overlap, a normalized nearest neighbor distance (NNND) measure was developed. For a given cell, the NNND is given by $2 R /\left(\sigma_{1}+\sigma_{2}\right)$, where $R$ is the distance between the centroid of the Gaussian fit to the receptive field and that of the nearest neighbor in the mosaic, and $\sigma_{1}$ and $\sigma_{2}$ are SDs of the fits measured along the line connecting the centroids. Thus, the NNND for a cell with a $1 \mathrm{SD}$ contour that abuts the $1 \mathrm{SD}$ contour of its nearest neighbor is 2 . Note that NNND is large when overlap is small, and vice versa. This representation has the advantages of being closely related to a standard anatomical measure (NND) and allowing for standardized comparison of overlap in different cell types.

\section{Results}

To probe the receptive field structure of individual SBCs and their spatial organization across the visual field, multielectrode recordings were obtained from peripheral pieces of macaque 
A

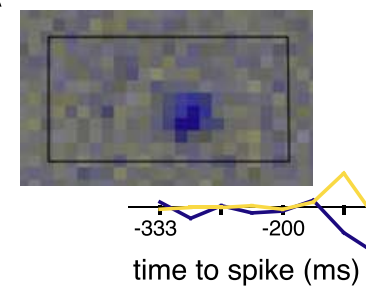

$\mathrm{C}$

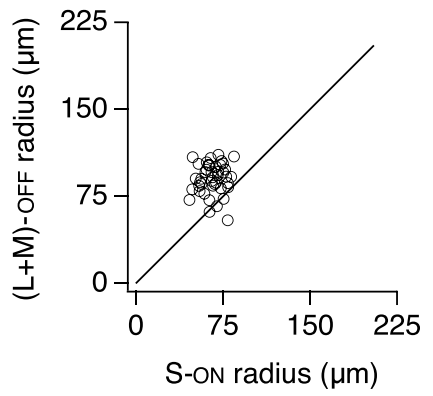

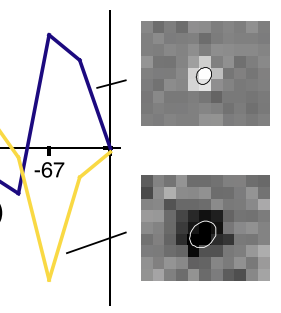

D

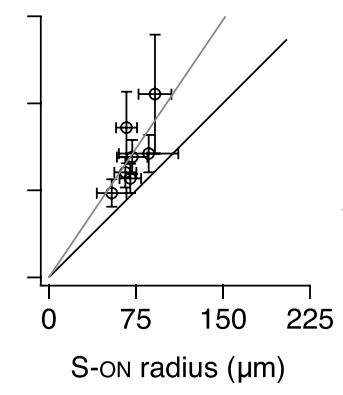

B

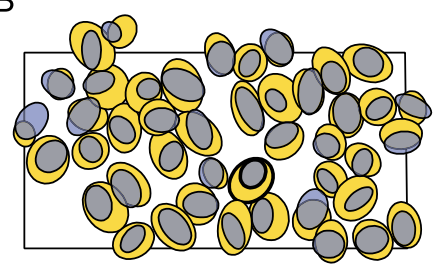

E

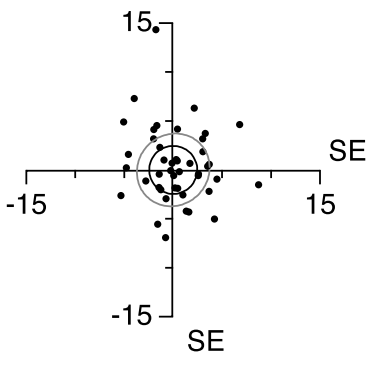

Figure 2. Spatial receptive field structure of SBCS. A, STA time course for an SBC computed from an $S$ versus $L+M$ coneisolating white noise stimulus (see Materials and Methods). The $S$ component is shown in blue, and the $L+M$ component in yellow. The vertical axis has arbitrary units. Left inset shows the spatial profile of both components combined, at the time of peak of the S-ON component. The rectangle indicates the outline of the electrode array (1800 $\mu \mathrm{m} \times 900 \mu \mathrm{m})$. Right insets show the spatial profiles of the $S$ (top) and $L+M$ (bottom) components in grayscale. Ellipses represent the $1 S D$ contours of Gaussian fits to the spatial profiles. $B$, One SD contours of Gaussian fits to the $S$ (blue) and $L+M$ (yellow) spatial profiles for 44 simultaneously recorded SBCs. Thick outline represents the cell shown in $A$. Rectangle is the outline of the array. $C, S$ and $L+M$ receptive field radii for the cells in $\boldsymbol{B}$. D. Mean \pm SD of $S$ compared with $L+M$ receptive field radii in seven preparations. Slope of best fit line (gray) is 1.48. $E$, Spatial offsets between the centroid of the Gaussian fit to the $L+M$ receptive field and that of the $S$ receptive field. Displacement for each cell is normalized by its measurement uncertainty (SE). Dark (light) circle indicates a displacement at the $p=0.05$ (0.001) significance level according to a $\chi^{2}$ test (see Materials and Methods). Same preparation as shown in $\boldsymbol{B}$.

spatial profiles of the S-ON and $(\mathrm{L}+\mathrm{M})$ OFF response components shown combined and separately. Also shown are the time courses of the two response components. The spatial profile of each component was fitted with a two-dimensional Gaussian (Fig. 2A, insets) (see Materials and Methods). For this cell, the spatial extent of the S-ON response component is clearly smaller than that of the $(\mathrm{L}+\mathrm{M})$ OFF response component. Figure $2 B$ shows the spatial profiles of the S-ON and $(\mathrm{L}+\mathrm{M})$-OFF responses for 44 simultaneously recorded SBCs in one preparation. The majority of cells in this preparation exhibited a smaller S-ON than ( $\mathrm{L}+\mathrm{M})$ OFF receptive field. This is summarized in Figure $2 C$, which shows the radius of the $\mathrm{S}-\mathrm{ON}$ region and the $(\mathrm{L}+\mathrm{M})-\mathrm{OFF}$ region on a cell-by-cell basis. The radius is that of the circle with an area equal to the area enclosed by the 1 SD contour of the Gaussian fit (see Materials and Methods). There was no indication of bimodality in the distribution of radii, implying that SBCs are not composed of type I and type II cells. Figure $2 D$ shows the mean $\mathrm{S}-\mathrm{ON}$ radius and the mean $(\mathrm{L}+\mathrm{M})$-OFF radius in seven preparations (252 SBCs). On average, the $(\mathrm{L}+\mathrm{M})$-OFF radius was $48 \%$ larger than the $\mathrm{S}-\mathrm{ON}$ radius; equivalently, the area was 2.2-fold larger.

Inspection of Figure $2 B$ suggests that the S-ON and $(\mathrm{L}+\mathrm{M})$-OFF components monkey retina in the presence of a white noise stimulus (Chichilnisky and Baylor, 1999; Litke et al., 2004). In a typical recording, spikes from several hundred RGCs were isolated, and their light response properties were characterized using reverse correlation with the stimulus. SBCs and parasol cells were identified based on response properties and density (Fig. 1) (see Materials and Methods).

\section{Center-surround receptive field structure}

Previous studies of RGCs with blue-ON/yellow-OFF (henceforth, S-ON/(L+M)-OFF) chromatic sensitivity have reported two distinct types of receptive field structure: type I, in which the $\mathrm{S}-\mathrm{ON}$ component forms the center and the ( $\mathrm{L}+\mathrm{M})$-OFF component forms the surround; and type II, in which the two components are spatially coextensive (Wiesel and Hubel, 1966; de Monasterio, 1978a,c; Derrington and Lennie, 1984). It is often assumed that SBCs are type II cells (Dacey, 1996; Rodieck, 1998), but this hypothesis has not been tested directly.

Coextensive receptive fields must have the same size and must be centered at the same location (Wiesel and Hubel, 1966). To test for these criteria, the retina was stimulated with spatiotemporal white noise that modulated $S$ cones independently from the combined modulation of $\mathrm{L}$ and $\mathrm{M}$ cones (see Materials and Methods). The spatiotemporal receptive field of each SBC was estimated by computing the STA stimulus (see Materials and Methods). This technique allowed the spatial profile and time course of the $\mathrm{S}-\mathrm{ON}$ response to be separated from that of the (L+M)-OFF response (Reid and Shapley, 2002).

Figure $2 A$ shows an example SBC receptive field, with the of the SBC receptive field may be spatially offset. To test this quantitatively, the spatial offset between the Gaussian fits to the two components was computed and plotted (Fig. 2E) relative to the confidence regions associated with uncertainty in the fits ( $p=0.05$ black, $p=0.001$ gray; see Materials and Methods). A majority of the data fell well outside these confidence regions, indicating statistically significant offsets between the two components of the receptive field for many cells. The mean offset in this preparation was $34 \%$ of receptive field center radius $(22 \mu \mathrm{m})$, comparable with the magnitude of offsets previously observed for midget cells (Lee et al., 1998).

Combined, the results illustrated in Figure 2 indicate that SBCs are unlikely to be the type II S-ON/(L+M)OFF cells reported previously (Wiesel and Hubel, 1966; de Monasterio, 1978a,c; Dacey, 1996, 2000). Instead, peripheral SBCs exhibit center-surround antagonism, with the S-ON component comprising the center and the $(\mathrm{L}+\mathrm{M})$-OFF component comprising the surround.

The $(\mathrm{L}+\mathrm{M})$-OFF response is slower than the $\mathrm{S}-\mathrm{ON}$ response A hypothesized origin of the $(\mathrm{L}+\mathrm{M})$-OFF signal in SBCs is that OFF-bipolar cells transmit L and M cone signals to SBC outer dendrites in the outer sublamina of the inner plexiform layer (Dacey and Lee, 1994; Calkins et al., 1998; Rodieck, 1998). However, the size discrepancy shown in Figure 2 raises the possibility that the $(\mathrm{L}+\mathrm{M})$-OFF component of the $\mathrm{SBC}$ receptive field, like the surround of parasol cells (McMahon et al., 2004), might instead be mediated by negative feedback from horizontal cells that collect inputs from cones over a large region (Dacey et al., 1996; 
Dacey, 2000; Packer and Dacey, 2002). The feedback would be expected to act on $S$ cones, endowing them with a surround. This center-surround structure would then propagate through S-ON bipolar cells, which contact the inner dendrites of SBCs (Kouyama and Marshak, 1992; Calkins et al., 1998; Dacey et al., 2000; Herr et al., 2003). In this scenario, the (L+M)OFF signal would be expected to be slower than the S-ON signal because of the additional synapse and propagation time involved in horizontal cell feedback.

Figure $3 A$ shows the $\mathrm{S}-\mathrm{ON}$ and $(\mathrm{L}+\mathrm{M})$-OFF response time courses for SBCs in three preparations. Time courses were obtained by averaging the STA over spatial locations at which the peak modulation amplitude was at least three times the SD of the noise; the noise was estimated from frames of the STA corresponding to times after the spike. For quantitative characterization, response time courses were fitted with a difference of low-pass filters (Chichilnisky and Kalmar, 2002) (Fig. 3B). Three quantities were extracted from these fits, each of which captures a different aspect of light response dynamics under the assumption that the cell integrates information linearly over time. First, the time to peak of the STA provides a measure of response latency. The time to peak of the $(\mathrm{L}+\mathrm{M})$-OFF time course in SBCs was delayed relative to that of the S-ON time course by $18.2 \pm 1.4$ $\mathrm{ms}$ (mean $\pm \mathrm{SD} ; 35 \%$ relative delay) (Fig. 3C, left). Second, the time to zero of the STA indicates the time of maximum response to a step change in illumination. The time to zero of the $(\mathrm{L}+\mathrm{M})$ OFF component was delayed relative to the $\mathrm{S}-\mathrm{ON}$ component by $31.4 \pm 3.9 \mathrm{~ms}$ ( $41 \%$ relative delay) (Fig. $3 C$, middle). Third, the degree of transiency indicates the fractional return to baseline response after a step change in illumination. It is given by $1-$ $\left(S / S_{\text {abs }}\right)$, where $S$ is the integral of the fitted time course, and $S_{\text {abs }}$ is the integral of its absolute value. The degrees of transiency of the S-ON and $(\mathrm{L}+\mathrm{M})$-OFF response components were statistically indistinguishable. The similar degree of transiency and the $\sim 40 \%$ increase in time to peak and time to zero imply that the major difference between the two response components is that the latter is expanded in time. This is consistent with the hypothesis that the SBC surround is mediated by horizontal cell feedback.

Comparison of response kinetics in parasol cells and SBCs provides further indirect evidence of horizontal cell involvement. The degree of transiency of RGC responses is thought to be established largely at the synapse between cones and bipolar cells, with transient (sustained) bipolar cell types feeding transient (sustained) RGC types (Awatramani and Slaughter, 2000; DeVries, 2000; DeVries et al., 2006). Anatomical studies have revealed that two diffuse OFF-bipolar cell types (DB2 and DB3) contact SBCs (Calkins et al., 1998); these bipolar cell types also provide the major input to OFF-parasol cells (Jacoby et al., 2000; Bordt et al., 2006). Therefore, if the DB2 and DB3 bipolar cells (rather than horizontal cell feedback) mediate a substantial com- ponent of the $(\mathrm{L}+\mathrm{M})-\mathrm{OFF}$ surround in $\mathrm{SBCs}$, one might expect a similar degree of transiency in SBC $(\mathrm{L}+\mathrm{M})$-OFF and OFFparasol responses. Contrary to this prediction, Figure $3 C$ (right) shows that the degree of transiency of the ( $\mathrm{L}+\mathrm{M})$-OFF response of SBCs is substantially smaller than that of simultaneously recorded OFF-parasol cells. This suggests that OFF-bipolar cells do not mediate a major component of the $(\mathrm{L}+\mathrm{M})$-OFF response in SBCs.

\section{The $(\mathrm{L}+\mathrm{M})$-OFF surround is eliminated by $\mathrm{L}-\mathrm{APB}$}

The above results on the spatial and temporal properties of SBC receptive fields provide circumstantial evidence that horizontal cells, rather than OFF-bipolar cells, mediate the $(\mathrm{L}+\mathrm{M})$-OFF response. A direct test of OFF-bipolar cell involvement is to bath apply the group III metabotropic glutamate receptor (mGluR) agonist L-APB (see Materials and Methods). L-APB blocks synaptic transmission from cones to ON-bipolar cells but not OFFbipolar cells (Slaughter and Miller, 1981) (see Discussion). Thus, if OFF-bipolar cells provide the (L+M)-OFF input to SBCs, $\mathrm{L}$-APB should eliminate the S-ON response and preserve the $(\mathrm{L}+\mathrm{M})$-OFF response.

The results of this experiment in a single recording of $22 \mathrm{SBCs}$ and 142 OFF-parasol cells are shown in Figure 4. The average time course and change in response amplitude are shown for the SBC S-ON, SBC (L+M)-OFF, and (for control purposes) OFFparasol cells. As expected, the $\mathrm{S}-\mathrm{ON}$ component of $\mathrm{SBC}$ responses was eliminated in the presence of L-APB (Fig. 4A,B). Surprisingly, the $(\mathrm{L}+\mathrm{M})$-OFF response was also eliminated (Fig. $4 C, D)$. 
A
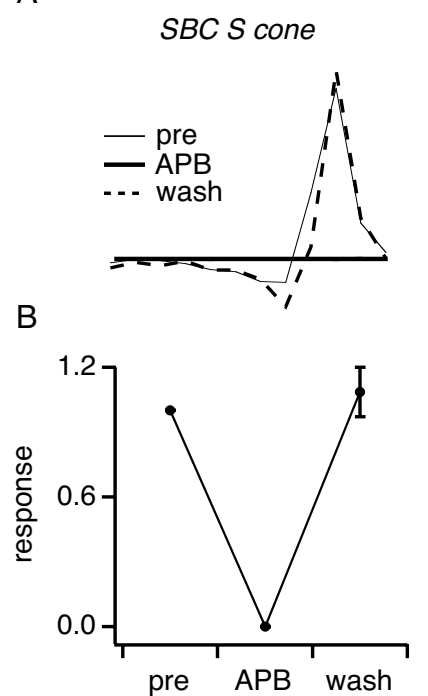

C
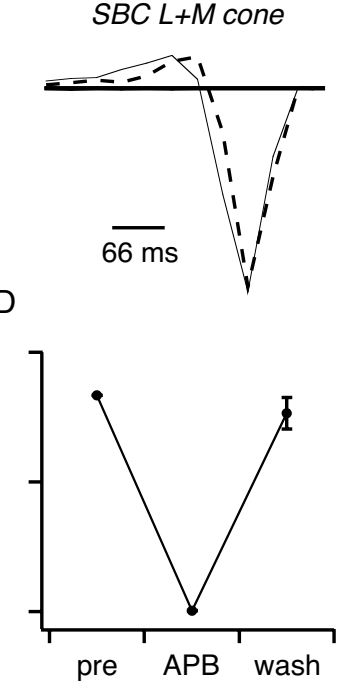

E

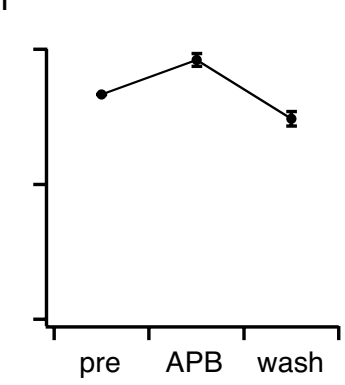

Figure 4. $\quad A P B$ attenuates the $(L+M)-0 F F$ response in $S B C S$. $A$, Average response time courses for the $S$ cone response in $S B C S$ before (line), during (thick line), and after (dashed line) application of L-APB in a single preparation with 22 SBCS and 142 OFF-parasol cells. $\boldsymbol{B}$, Change in response amplitude (see Materials and Methods) across conditions. $\boldsymbol{C}-\boldsymbol{F}$, Same as in $\boldsymbol{A}$ and $\boldsymbol{B}$, but for the $(\mathrm{L}+\mathrm{M})$-OFF response in SBCS $(\boldsymbol{C}, \boldsymbol{D})$ and OFF-parasol cells $(\boldsymbol{E}, \boldsymbol{F})$.

In contrast, OFF-parasol cells showed no change in response kinetics with L-APB, but did show a statistically significant increase in response amplitude (Fig. $4 E, F$ ). This increase is probably the result of blocking inhibition to OFF RGCs provided by the ON pathway (Zaghloul et al., 2003; Margolis and Detwiler, 2007). Similar results were obtained in a second preparation: the SBC $\mathrm{S}-\mathrm{ON}$ and $(\mathrm{L}+\mathrm{M})$-OFF response was reduced to $<1 \%$ of original amplitude (seven cells), and OFF-parasol cell response amplitude increased by $30 \pm 5 \%$ ( 50 cells).

These results indicate that OFF-bipolar cells provide little if any functional input to SBCs in the present conditions. In the discussion, it is proposed that $\mathrm{SBC}$ receive dominant $\mathrm{L}+\mathrm{M}$ cone input via H2 horizontal cell feedback (Dacey, 2000; Herr et al., 2003; Schein et al., 2004).

\section{Mosaic organization of receptive fields: regularity, size, and overlap}

Encoding of the visual scene is determined not only by the receptive field properties of individual cells, but also by how regularly and completely the entire collection of cells samples visual space. Previous anatomical and physiological work indicates that at least some types of RGCs form orderly mosaics that regularly and uniformly cover the surface of the retina (Wassle and Riemann, 1978; Dacey, 1993b; DeVries and Baylor, 1997; Chichilnisky and Kalmar, 2002; Frechette et al., 2005) (but see Segev et al., 2006). However, the mosaic organization of SBC receptive fields has been neither established nor characterized.

Figure 5 shows collections of SBC receptive fields recorded simultaneously in six preparations. The ellipses in each panel show the 1 SD contours of Gaussian fits to the $\mathrm{S}-\mathrm{ON}$ receptive field component (see Materials and Methods). The rectangles represent the outline of the electrode array. Visual inspection suggests that the receptive fields of SBCs recorded in each preparation form an orderly mosaic: a random distribution of receptive fields would be expected to exhibit substantial overlap and gaps not observed in the data (see below). For two preparations, the receptive fields of simultaneously recorded ON-parasol cells are also shown. ON-parasol cells have been shown to exhibit regular mosaic organization in previous ana-

tomical and physiological studies (Dacey, 1993b; Chichilnisky and Kalmar, 2002; Frechette et al., 2005).

To test SBC mosaic organization quantitatively, the regularity of receptive field spacing was compared with that expected of random spacing. Spacing was measured by computing the NND for each cell in the mosaic (Wassle and Riemann, 1978). The NND is the distance between the centroids of the Gaussian fits to the receptive field of the reference cell and that of its nearest neighbor. The distribution of NNDs for all SBCs in a single recording is shown in Figure $6 \mathrm{~A}$. The data reveal that the typical spacing between cells in this preparation is $\sim 135$ $\mu \mathrm{m}$. Notably lacking, however, are pairs of cells spaced by $<60 \mu \mathrm{m}$. This local exclusion is a signature of mosaic organization. The smooth curve in the figure represents the distribution of NND values for a randomly distributed collection of receptive fields with matching density (see Materials and Methods). As expected, the random distribution includes a much broader range of cell spacings. The inset in Figure $6 \mathrm{~A}$ shows the observed receptive field mosaic and a collection of randomly placed receptive fields. The random placement produces substantial overlap and gaps, features absent in the data (Fig. 5). For each of the 18 preparations tested, the difference between the observed and random NND distributions was significant ( $p<0.0001 ; \mathrm{K}-\mathrm{S}$ test, see Materials and Methods).

Three basic properties of mosaic organization characterize the population sampling of the visual scene: regularity of receptive field spacing, regularity of receptive field size, and receptive field overlap. Each of these features may influence the spatial resolution and reliability of the visual representation (Zhang and Reid, 2005). Below, these properties are quantified for SBC receptive field mosaics and compared with those of ON-parasol cells.

\section{Spacing}

The spacing regularity of each mosaic was quantified by computing the CR (mean/SD) of the NND distribution. A high CR indicates regular spacing (Wassle and Riemann, 1978; Cook, 1996). To avoid biases in the estimation of CR, cells in the mosaic abutting substantial gaps were excluded (see Materials and Methods). For the distribution in Figure 6A, the CR was 5.9. ON-parasol cells provide a natural comparison for the regularity of SBC mosaic organization. The distribution of NNDs for ON-parasol cells recorded simultaneously with the SBCs of Figure $6 A$ is shown in the same panel. The CR of the observed data is 7.7. The CRs for SBCs and ON-parasol cells simultaneously recorded in 18 preparations are shown in Figure $6 \mathrm{~B}$. Although the CRs varied considerably across preparations, on average the two cell types exhibited similar mosaic regularity, with a CR of $7.3 \pm 0.4$ (mean $\pm \mathrm{SE}$ ) for SBCs and a CR of $7.6 \pm 0.4$ for ON-parasol cells. A comparison of these physiological CRs with anatomically measured CRs of other retinal cell types is included in the Discussion.

\section{Size}

Although the spacing regularity of SBCs is similar to that of ON-parasol cells, the variation in size of individual receptive fields appears to be 
small bistratified

retina 1

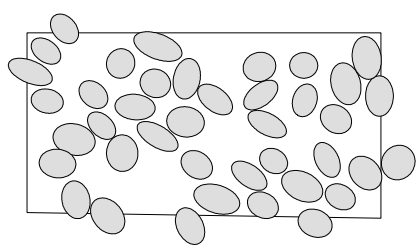

retina 3

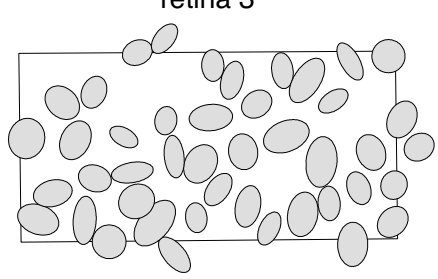

retina 2

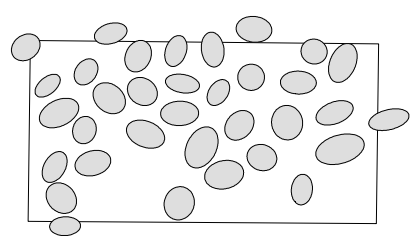

retina 4

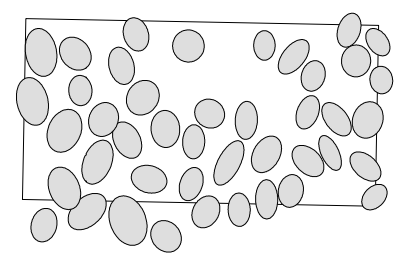

ON-parasol

retina 5

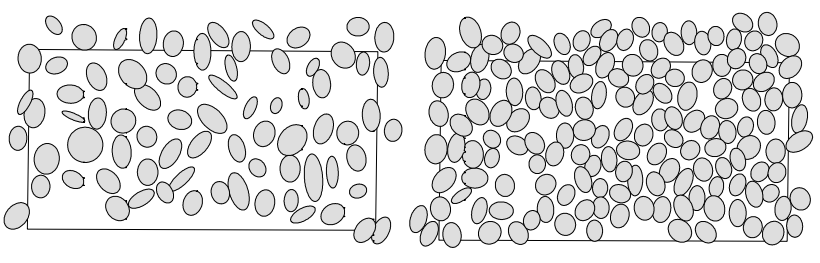

retina 6
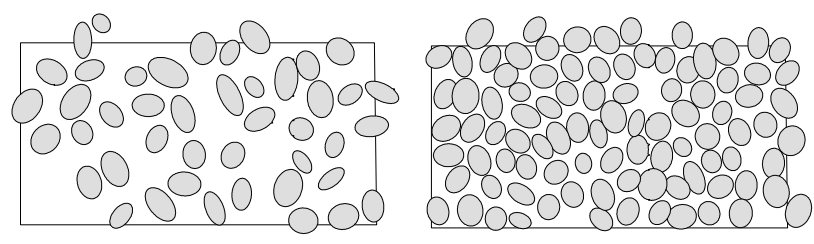

Figure 5. Mosaics of small bistratified and ON-parasol cell receptive fields. Data are from six retinas. SBC receptive fields from retinas 1-4. Spatial profile of each cell is represented by the 1 SD contour of a two-dimensional Gaussian fit. Retinas 5 and 6 show simultaneously recorded SBC (left) and ON-parasol cell (right) receptive fields. Rectangles indicate the outline of the electrode array $(1800 \mu \mathrm{m} \times 900 \mu \mathrm{m})$.

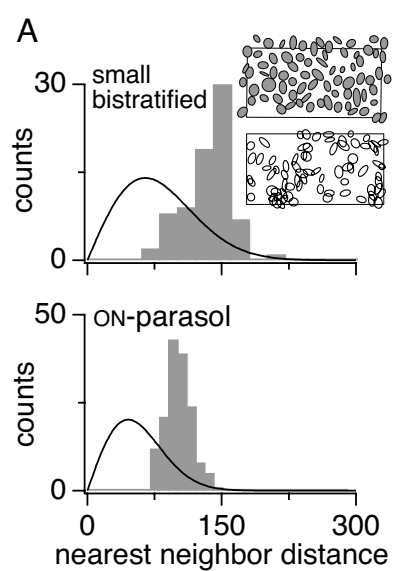

\section{B}

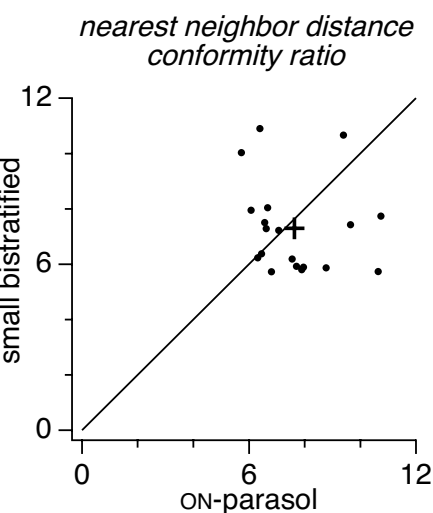

Figure 6. Mosaic regularity. A, Gray histograms show distributions of NNDs for a collection of SBCs and $0 \mathrm{~N}$-parasol cells recorded in one preparation (retina $5 \mathrm{in} \mathrm{Fig.} \mathrm{5).} \mathrm{NND} \mathrm{was} \mathrm{based} \mathrm{on} \mathrm{the}$ center point (mean) of the Gaussian fits. Smooth curves show NND distributions expected from random placement of the observed number of cells (see Materials and Methods). Insets show the SBC mosaic (top) and a simulated mosaic of cells placed randomly (bottom). B, Scatter plot of NND distribution conformity ratios of SBC versus those of simultaneously recorded ONparasol cells for 19 preparations (see Materials and Methods). The cross indicates SBC and ON-parasol NND mean (and SE) conformity ratios over these preparations.

larger for SBCs (Fig. 5, retinas 5 and 6). Comparison of the receptive field sizes across 31 preparations (Fig. $7 A$ ) showed that the average SBC receptive field size was slightly $(10 \%)$ larger, but the CR of receptive field size was substantially lower (67\%) than that of ON-parasol cells (Fig. $7 B)$. Thus, although SBC and ON-parasol cell receptive fields exhibited comparable variability in spacing, SBC receptive fields showed a greater variability in size.

\section{Overlap}

Receptive field overlap was characterized by computing the distribution of NNNDs for all cells in the mosaic. The NNND is the NND normalized by the spatial extent of the individual receptive fields, defined by Gaussian fits (see Materials and Methods). A NNND value of 2, for example, indicates that the receptive fields of two cells meet at the 1 SD contours of the respective Gaussian fits. Example NNND distributions for SBCs and ON-parasol cells
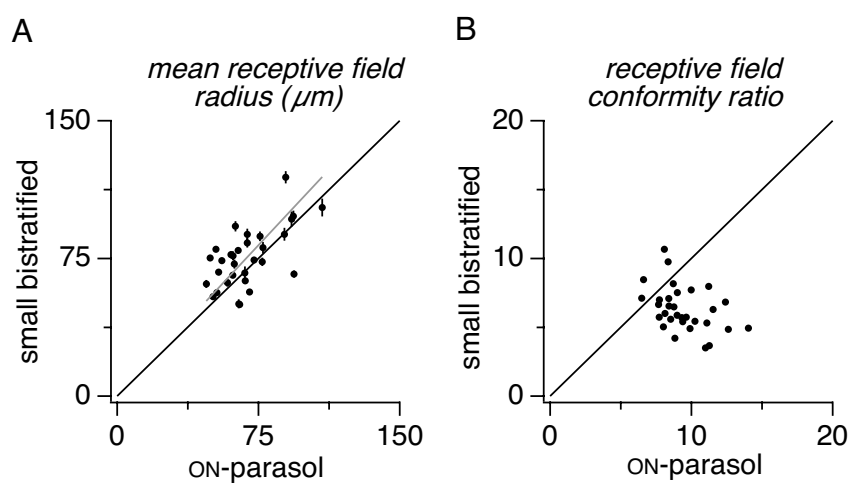

Figure 7. Receptive field size and its variability. $A$, Scatter plot compares the mean SBC and ON-parasol receptive field radii across 31 preparations. Error bars span $\pm 1 \mathrm{SE}$. First-degree polynomial with zero intercept fit to the data (gray line) has a slope of 1.10. B, Scatter plot compares conformity ratio of the distribution of receptive field sizes for SBC and ON-parasol cells for same preparations as in $\boldsymbol{A}$.

from a single recording are shown in Figure $8, A$ and $B$. The observed NNND values are clustered around 2. To summarize the average overlap, the mode of the NNND distribution was identified by calculating the mean of the densest $75 \%$ of points in the distribution. Across 18 data sets, this value was $2.30 \pm 0.18$ (mean $\pm \mathrm{SE}$ ). The modal NNND exhibited little or no dependence on the retinal eccentricity of the recording (Fig. 8C) and therefore appears to represent an invariant property of SBCs across the peripheral visual field. Figure $8 D$ compares the modal NNND values for SBCs and ON-parasol cells in 18 preparations. On average, ON-parasol mosaics exhibited modal NNND values of $1.83 \pm 0.03$, which is $\sim 20 \%$ lower than that of SBC mosaics. Thus, two populations of cells with similar single cell spatial extent (Fig. $7 A$ ) can exhibit systematic differences in receptive field overlap.

\section{Discussion}

We characterized the receptive field structure and collective spatial sampling properties of SBCs in peripheral primate retina. The receptive fields of individual SBCs exhibited center-surround antagonism. SBC color opponency did not arise from pooling ON- and OFF- 
A
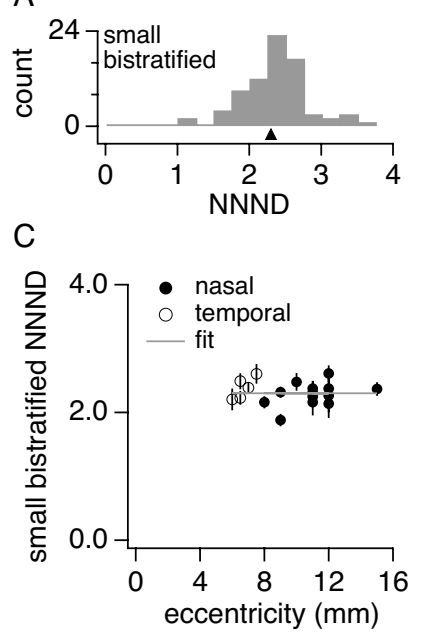

$\mathrm{B}$

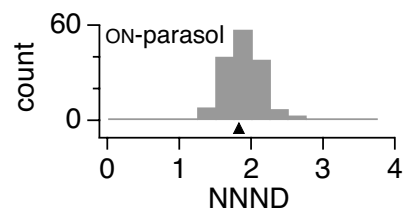

$\mathrm{D}$

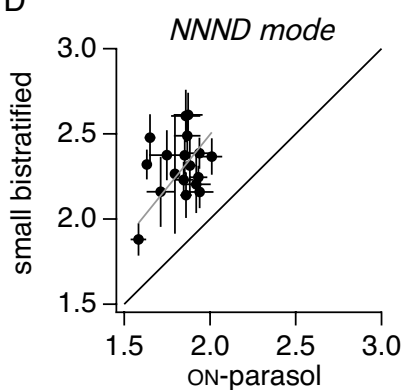

Figure 8. Mosaic overlap. $\boldsymbol{A}$, Histogram of normalized nearest neighbor distances (NNND) for SBCs from retina 5 in Figure 5. Black triangle shows the mean of densest $75 \%$ (mode) of the distribution. $\boldsymbol{B}$, Histogram of NNNDs for $0 \mathrm{~N}$-parasol cells recorded simultaneously with the SBCS in $\boldsymbol{A}$. C, NNND modes for SBCs from 18 preparations across retinal eccentricities $6-15 \mathrm{~mm}$ from the fovea. Nasal (temporal) recordings are shown in filled (open) circles with SE. Line is a zero slope fit to the data yielding a mean NNND across eccentricities of $2.30 \pm 0.18$. D, Scatter plot comparing NNND modes and SEs for simultaneously recorded SBCs and ON-parasol cells. Regression line with zero intercept has a slope of 1.25 .

bipolar cell signals. Instead, the data suggested that horizontal cells provide the (L+M)-OFF surround (Dacey, 2000; Herr et al., 2003; Schein et al., 2004). The receptive fields of SBCs formed nonrandom mosaics with overlap and regularity similar to those of ON-parasol cells. These findings indicate that SBC receptive fields exhibit two basic properties of other RGC types: center-surround antagonism and regular mosaic sampling of the visual scene.

\section{SBC receptive fields exhibit center-surround antagonism}

The finding that SBCs exhibit center-surround antagonist complements previous studies in primate LGN and retina (Wiesel and Hubel, 1966; de Monasterio and Gouras, 1975; de Monasterio, 1978b). Although the LGN study observed more blue-yellow cells with spatially coextensive (type II) receptive fields (15 of 21), the retinal studies observed more center-surround (type I) cells (41 of 53) (de Monasterio and Gouras, 1975; de Monasterio, $1978 \mathrm{a}, \mathrm{c})$. One study questioned whether the type I/II distinction was a quantitative one (Derrington and Lennie, 1984). Unfortunately, morphological identification was absent in these studies. Later studies in which SBC physiology was characterized simultaneously with morphology either did not report receptive field structure (Dacey and Lee, 1994) or provided limited data (Dacey, 1996).

Taking into account the large number (17-22) of RGC types in the primate retina and that at least two cell types (SBCs and LBCs) exhibit S-ON/(L+M)-OFF opponency (Dacey et al., 2003, 2005), it is possible that previously reported type II cells correspond to a different RGC type. It is also possible that SBCs in central retina are more often type II and/or that preferential blurring of short-wavelength light by the optics of the eye caused SBC receptive fields to appear closer to type II in vivo (Bedford and Wyszecki, 1957; Calkins et al., 1998; but see McLellan et al., 2002). Finally, it is possible that circuitry in the LGN diminishes spatial opponency in blue-yellow cells.

\section{Circuitry for chromatic and spatial opponency}

The primary implication of the present results for the circuitry underlying color opponency in SBCs is that OFF-bipolar cells contribute little to the $(\mathrm{L}+\mathrm{M})$-OFF response. The principal evidence for this conclusion is that L-APB, an agonist of mGluR6 receptors that blocks transmission between photoreceptors and ON-bipolar cells, nearly eliminated the $(\mathrm{L}+\mathrm{M})$-OFF response in SBCs. The limited role of OFF-bipolars is also suggested by the large difference in the degree of transiency between the $(\mathrm{L}+\mathrm{M})$ OFF responses of SBCs and OFF-parasol cells. Specifically, the degree of transiency of RGC responses is thought to be established largely at the synapse between cones and bipolars (Awatramani and Slaughter, 2000; DeVries, 2000; DeVries et al., 2006), yet the DB2 and DB3 OFF-bipolar cells that provide input to OFF-parasol cells are the only OFF-bipolar cells appropriately positioned to provide input to SBCs (Calkins et al., 1998; Jacoby et al., 2000; Bordt et al., 2006). Thus, a large role for OFF-bipolars would seem to imply a more similar degree of transiency in SBCs and OFF-parasol cells than was observed.

One caveat to the pharmacological evidence is that L-APB, a group III mGluR agonist, has been shown to suppress EPSC frequency in OFF-RGCs in salamander retina, likely through the activation of either mGluR4 or mGluR8 expressed in OFFbipolar cell terminals (Awatramani and Slaughter, 2001; Higgs et al., 2002). However, experiments in guinea pig showed that L-APB did not reduce the light response of OFF- $\alpha$ RGCs (Zaghloul et al., 2003). Additionally, in the present study, L-APB had a net effect of enhancing response amplitude in simultaneously recorded OFF-parasol cells, probably through the suppression of inhibition from the ON-pathway (Fig. 4) (Zaghloul et al., 2003; Margolis and Detwiler, 2007). Thus, the dominant effect of L-APB in this study is likely to be the blocking of transmission from photoreceptors to ON-bipolar cells.

A secondary implication of the present findings is that the $(\mathrm{L}+\mathrm{M})$-OFF response arises from negative feedback onto $S$ cones by horizontal cells. This interpretation is speculative. Horizontal cell feedback is thought to be the dominant mechanism generating receptive field surrounds in mammalian retina (Mangel, 1991; Dacey, 2000; McMahon et al., 2004). H1 horizontal cells are excluded because they appear to avoid the $\mathrm{S}$ cone pathway altogether. This leaves $\mathrm{H} 2$ cells, which contact all three primate cone types, and make dense contacts with S cones (Kolb et al., 1980; Boycott et al., 1987; Ahnelt and Kolb, 1994; Dacey et al., 1996; Wassle et al., 2000). The H2 cell feedback interpretation is consistent with the results of the L-APB experiment and is supported by both the time delay of the $(\mathrm{L}+\mathrm{M})$-OFF relative to the S-ON response and the center-surround structure of $\mathrm{SBC}$ receptive fields, which would be expected if horizontal cell feedback pooled cone inputs over a large area (Packer and Dacey, 2002). Furthermore, the similarity in the degree of transiency in the S-ON and $(\mathrm{L}+\mathrm{M})$-OFF signals in SBCs suggests that these two response components may be conveyed by a single bipolar cell type (DeVries et al., 2006), possibly after the site of combination of the $\mathrm{S}-\mathrm{ON}$ and $(\mathrm{L}+\mathrm{M})$-OFF signals. An interesting corollary of the horizontal cell hypothesis is that one mechanism creates both spatial and chromatic opponency in SBCs.

An alternative hypothesis is that the surround is mediated by amacrine cells (Cook and McReynolds, 1998; Lukasiewicz, 2005). Amacrine cells make extensive contacts to the inner and outer dendrites of SBCs (Calkins et al., 1998; Ghosh and Grunert, 1999). In guinea pig and mouse, the ON pathway provides tonic inhibition to OFF- $\alpha$ RGCs, perhaps via a bistratified, ONamacrine cell (Zaghloul et al., 2003; Margolis and Detwiler, 
2007). If such a circuit provides inhibition to OFF-parasol cells, it may also provide inhibition to the costratifying SBC outer dendrites. Also, some ON-bipolar cells have a high rate of tonic glutamate release that probably tracks glutamate release from cones (Zaghloul et al., 2003). If S cone bipolar cells (an ON-type cell) have the same property, then the release of tonic inhibition from an $\mathrm{ON}$-amacrine cell collecting $\mathrm{L}$ and $\mathrm{M}$ cone inputs could permit spikes in the SBC, producing an OFF response. The present observation that L-APB silenced SBCs (Fig. 4) and caused an increase in the spike rate of OFF-parasol cells (data not shown) is consistent with this model. Of course, both horizontal cells and amacrine cells may contribute to the SBC surround. Interestingly, a recent study suggests that amacrine cells mediate surrounds in the presence of low-contrast stimuli, whereas horizontal cells dominate in the presence of high-contrast stimuli (Ichinose and Lukasiewicz, 2005). Intracellular recordings from SBCs and other cells of the $S$ cone pathway will be needed to distinguish these possibilities.

The reported results beg the question of why there appear to be contacts between SBC outer dendrites and OFF-bipolar cells. One possibility is that the $(\mathrm{L}+\mathrm{M})$-OFF signal is provided by different pathways in central versus peripheral retina: anatomical studies demonstrating such contacts were performed in foveal retina (Calkins et al., 1998), whereas the present experiments were performed in peripheral retina. One study of peripheral marmoset retina observed that a small minority (7\%) of SBC outer dendrite synapses were associated with OFF-bipolar cells, and the remainder of the synapses were with amacrine cells (Ghosh and Grunert, 1999). A possibility that cannot be excluded by the present data is that OFF-bipolar cells provide facilitatory input that rarely causes the SBC membrane potential to cross spike threshold. It is also possible that the primary role of the outer dendrites is to collect tonic inhibition from the ONpathway via amacrine cells (see above). Amacrine cell input could also shape response kinetics, contribute to adaptation, or provide a nonclassical surround to SBCs (Nirenberg and Meister, 1997; McMahon et al., 2004; Hosoya et al., 2005; Zaghloul et al., 2007).

\section{Mosaics: a general feature of RGC organization}

Anatomical studies have revealed mosaic spatial organization in every major retinal cell class (Fig. 9): photoreceptors (de Monasterio et al., 1981), horizontal cells (Wassle and Riemann, 1978), bipolar cells (Young and Vaney, 1991; Kouyama and Marshak, 1997), amacrine cells (Vaney et al., 1991; Eglen et al., 2003), and RGCs (Wassle and Riemann, 1978; Wassle et al., 1981; Dacey, 1993b). Although several different techniques have been used to characterize the regularity of spatial arrangement (Rodieck, 1991; Cook, 1996; Zhan and Troy, 2000), by far the most common measure is CR of the nearest neighbor distances. Interestingly, anatomical studies have observed a wide range of values, from those corresponding to nearly random arrangements (Luo et al., 1999; Galli-Resta et al., 2000) to those indicating highly regular and packing-limited arrangements (Wassle and Riemann, 1978; Dacey, 1993b). The present work reveals for the first time the regularity of receptive field mosaics of RGCs of known types.

Figure 9 shows a comparison of the measured CR of SBC and ON-parasol receptive field mosaics to the CR of anatomical mosaics from previous studies. Surprisingly, SBC and ON-parasol receptive field mosaics exhibited greater regularity than all anatomical mosaics except for human midget RGCs and packinglimited cones in the central visual field (Wassle and Riemann, 1978; Curcio et al., 1990; Dacey, 1993b). In addition, some of the most complete receptive field mosaics observed exhibited CRs

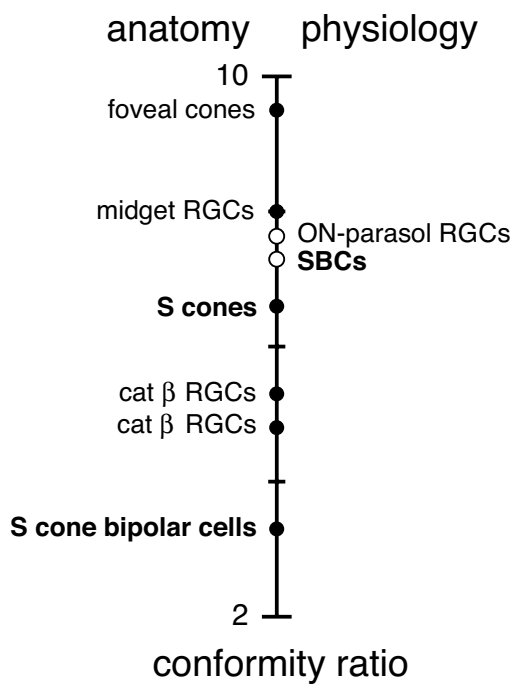

Figure 9. Comparison of anatomical and functional mosaic regularity. Anatomical mosaic CRs were based on cell soma positions and are taken from the literature (Wassle and Riemann, 1978; Wassle et al., 1981; Curcio et al., 1990; Dacey, 1993b; Kouyama and Marshak, 1997). All values are from primate except where noted. Physiological mosaic regularity is based on receptive field center locations. Note that the CR for SBCs and ON-parasol cells were not statistically different (Fig. 6B). For comparison, random mosaics have an expected CR of 1.913 (Cook, 1996).

$>10$, in excess of all reported values in the anatomical literature. Interestingly, $\mathrm{S}$ cones and $\mathrm{S}$ cone bipolar cells in the macaque exhibit substantially lower anatomical regularity than the functional regularity of SBC receptive fields (Kouyama and Marshak, 1997). This suggests that synaptic connections linking cells of the $S$ cone pathway, perhaps via activity-dependent refinement, increase the regularity of receptive field mosaics beyond that established by cell body placement (Sernagor et al., 2001).

In contrast to findings in primate and rabbit (DeVries and Baylor, 1997; Chichilnisky and Kalmar, 2002; Frechette et al., 2005), a recent study of salamander retina suggested that many RGC types may not form a receptive field mosaic organization (Segev et al., 2006). Possible explanations for this discrepancy are that it is more difficult to distinguish the distinct RGC types in larval tiger salamander than in mammalian retina or that largescale recordings provide a more clear view of functional distinctions between cell types. The present findings, and the recent discovery of another cell type that forms a receptive field mosaic (Petrusca et al., 2007), suggest that receptive field mosaic organization is a general feature of mammalian RGCs. This view of retinal architecture is consistent with anatomical studies in many species (Field and Chichilnisky, 2007). The unambiguous functional distinctions observed in large-scale recordings (Fig. 1), along with mosaic organization, confirm the irreducibility of each RGC type and hold promise for comprehensive characterization of the 17-22 anatomically distinct RGC types in primate retina. The present findings also raise the question of whether cell location and dendritic morphology, or alternatively the patterns of synaptic connectivity, are more important for producing receptive field mosaics. Future work may provide insight into how other cell types subserving important visual functions, such as the numerous midget cells, sample visual space.

\section{References}

Ahnelt P, Kolb H (1994) Horizontal cells and cone photoreceptors in primate retina: a golgi-light microscopic study of spectral connectivity. J Comp Neurol 343:387-405. 
Awatramani GB, Slaughter MM (2000) Origin of transient and sustained responses in ganglion cells of the retina. J Neurosci 20:7087-7095.

Awatramani GB, Slaughter MM (2001) Intensity-dependent, rapid activation of presynaptic metabotropic glutamate receptors at a central synapse. J Neurosci 21:741-749.

Bedford RE, Wyszecki G (1957) Axial chromatic aberration of the human eye. J Opt Soc Am 47:564-565.

Bordt AS, Hoshi H, Yamada ES, Perryman-Stout WC, Marshak DW (2006) Synaptic input to off parasol ganglion cells in macaque retina. J Comp Neurol 498:46-57.

Boycott BB, Hopkins JM, Sperling HG (1987) Cone connections of the horizontal cells of the rhesus monkey's retina. Proc R Soc Lond B Biol Sci 229:345-379.

Calkins DJ, Tsukamoto Y, Sterling P (1998) Microcircuitry and mosaic of a blue-yellow ganglion cell in the primate retina. J Neurosci 18:3373-3385.

Castleman KR (1996) Digital image processing. Englewood Cliffs, NJ: Prentice Hall.

Chichilnisky EJ (2001) A simple white noise analysis of neuronal light responses. Network 12:199-213.

Chichilnisky EJ, Baylor DA (1999) Receptive-field microstructure of blueyellow ganglion cells in primate retina. Nat Neurosci 2:889-893.

Chichilnisky EJ, Kalmar RS (2002) Functional asymmetries in on and off ganglion cells of primate retina. J Neurosci 22:2737-2747.

Cook JE (1996) Spatial properties of retinal mosaics: an empirical evaluation of some existing measures. Vis Neurosci 13:15-30.

Cook PB, McReynolds JS (1998) Lateral inhibition in the inner retina is important for spatial tuning of ganglion cells. Nat Neurosci 1:714-719.

Croner LJ, Kaplan E (1995) Receptive fields of p and m ganglion cells across the primate retina. Vision Res 35:7-24.

Curcio CA, Sloan KR, Kalina RE, Hendrickson AE (1990) Human photoreceptor topography. J Comp Neurol 292:497-523.

Dacey DM (1993a) Morphology of a small-field bistratified ganglion cell type in the macaque and human retina. Vis Neurosci 10:1081-1098.

Dacey DM (1993b) The mosaic of midget ganglion cells in the human retina. J Neurosci 13:5334-5355.

Dacey DM (1996) Circuitry for color coding in the primate retina. Proc Natl Acad Sci USA 93:582-588.

Dacey DM (2000) Parallel pathways for spectral coding in primate retina. Annu Rev Neurosci 23:743-775.

Dacey DM (2004) Origins of perception: retinal ganglion cell diversity and the creation of parallel visual pathways. In: The cognitive neurosciences (Gazzaniga MS, ed), pp 281-301. Cambridge, MA: MIT.

Dacey DM, Lee BB (1994) The 'blue-on’ opponent pathway in primate retina originates from a distinct bistratified ganglion cell type. Nature 367:731-735.

Dacey DM, Packer OS (2003) Colour coding in the primate retina: diverse cell types and cone-specific circuitry. Curr Opin Neurobiol 13:421-427.

Dacey DM, Lee BB, Stafford DK, Pokorny J, Smith VC (1996) Horizontal cells of the primate retina: cone specificity without spectral opponency. Science 271:656-659.

Dacey DM, Packer OS, Diller L, Brainard D, Peterson B, Lee B (2000) Center surround receptive field structure of cone bipolar cells in primate retina. Vision Res 40:1801-1811.

Dacey DM, Peterson BB, Robinson FR, Gamlin PD (2003) Fireworks in the primate retina: in vitro photodynamics reveals diverse lgn-projecting ganglion cell types. Neuron 37:15-27.

Dacey DM, Liao HW, Peterson BB, Robinson FR, Smith VC, Pokorny J, Yau KW, Gamlin PD (2005) Melanopsin-expressing ganglion cells in primate retina signal colour and irradiance and project to the lgn. Nature 433:749-754.

de Monasterio FM (1978a) Properties of concentrically organized $x$ and $y$ ganglion cells of macaque retina. J Neurophysiol 41:1394-1417.

de Monasterio FM (1978b) Center and surround mechanisms of opponentcolor $\mathrm{x}$ and $\mathrm{y}$ ganglion cells of retina of macaques. J Neurophysiol 41:1418-1434.

de Monasterio FM (1978c) Properties of ganglion cells with atypical receptive-field organization in retina of macaques. J Neurophysiol 41:1435-1449.

de Monasterio FM, Gouras P (1975) Functional properties of ganglion cells of the rhesus monkey retina. J Physiol (Lond) 251:167-195.

de Monasterio FM, Schein SJ, McCrane EP (1981) Staining of blue-sensitive cones of the macaque retina by a fluorescent dye. Science 213:1278-1281.
Derrington AM, Lennie P (1984) Spatial and temporal contrast sensitivities of neurones in lateral geniculate nucleus of macaque. J Physiol (Lond) 357:219-240.

DeVries SH (2000) Bipolar cells use kainate and ampa receptors to filter visual information into separate channels. Neuron 28:847-856.

DeVries SH, Baylor DA (1997) Mosaic arrangement of ganglion cell receptive fields in rabbit retina. J Neurophysiol 78:2048-2060.

DeVries SH, Li W, Saszik S (2006) Parallel processing in two transmitter microenvironments at the cone photoreceptor synapse. Neuron 50:735-748.

Drasdo N, Fowler CW (1974) Non-linear projection of the retinal image in a wide-angle schematic eye. Br J Ophthalmol 58:709-714.

Duda RO, Hart PE, Stork DG (2001) Pattern classification. New York: Wiley.

Eglen SJ, Raven MA, Tamrazian E, Reese BE (2003) Dopaminergic amacrine cells in the inner nuclear layer and ganglion cell layer comprise a single functional retinal mosaic. J Comp Neurol 466:343-355.

Estevez O, Spekreijse H (1982) The "silent substitution" method in visual research. Vision Res 22:681-691.

Field GD, Chichilnisky EJ (2007) Information processing in the retina: circuitry, coding, and mechanism. Annu Rev Neurosci 30:1-30.

Frechette ES, Sher A, Grivich MI, Petrusca D, Litke AM, Chichilnisky EJ (2005) Fidelity of the ensemble code for visual motion in primate retina. J Neurophysiol 94:119-135.

Galli-Resta L, Novelli E, Volpini M, Strettoi E (2000) The spatial organization of cholinergic mosaics in the adult mouse retina. Eur J Neurosci 12:3819-3822.

Ghosh KK, Grunert U (1999) Synaptic input to small bistratified (blue-on) ganglion cells in the retina of a new world monkey, the marmoset Callithrix jacchus. J Comp Neurol 413:417-428.

Ghosh KK, Martin PR, Grunert U (1997) Morphological analysis of the blue cone pathway in the retina of a new world monkey, the marmoset Callithrix jacchus. J Comp Neurol 379:211-225.

Haverkamp S, H Wassle (2004) Characterization of an amacrine cell type of the mammalian retina immunoreactive for vesicular glutamate transporter 3. J Comp Neurol 468:251-263.

Herr S, Klug K, Sterling P, Schein S (2003) Inner s-cone bipolar cells provide all of the central elements for $\mathrm{s}$ cones in macaque retina. J Comp Neurol 457:185-201.

Higgs MH, Romano C, Lukasiewicz PD (2002) Presynaptic effects of group iii metabotropic glutamate receptors on excitatory synaptic transmission in the retina. Neuroscience 115:163-172.

Hosoya T, Baccus SA, Meister M (2005) Dynamic predictive coding by the retina. Nature 436:71-77.

Ichinose T, Lukasiewicz PD (2005) Inner and outer retinal pathways both contribute to surround inhibition of salamander ganglion cells. J Physiol (Lond) 565: 517-535.

Jackson JE (1991) A user's guide to principal components. New York: Wiley-Interscience.

Jacoby RA, Wiechmann AF, Amara SG, Leighton BH, Marshak DW (2000) Diffuse bipolar cells provide input to off parasol ganglion cells in the macaque retina. J Comp Neurol 416:6-18.

Kolb H, Mariani A, Gallego A (1980) A second type of horizontal cell in the monkey retina. J Comp Neurol 189:31-44.

Kouyama N, Marshak DW (1992) Bipolar cells specific for blue cones in the macaque retina. J Neurosci 12:1233-1252.

Kouyama N, Marshak DW (1997) The topographical relationship between two neuronal mosaics in the short wavelength-sensitive system of the primate retina. Vis Neurosci 14:159-167.

Kuffler SW (1953) Discharge patterns and functional organization of mammalian retina. J Neurophysiol 16:37-68.

Lee BB (1996) Receptive field structure in the primate retina. Vision Res 36:631-644.

Lee BB, Kremers J, Yeh T (1998) Receptive fields of primate retinal ganglion cells studied with a novel technique. Vis Neurosci 15:161-175.

Litke AM, Bezayiff N, Chichilnisky EJ, Cunningham W, Dabrowski W, Grillo AA, Grivich M, Grybos P, Hottowy P, Kachiguine S, Kalmar RS, Mathieson K, Petrusca D, Rahman M, Sher A (2004) What does the eye tell the brain? Development of a system for the large scale recording of retinal output activity. IEEE Trans Nucl Sci 1434-1440.

Lukasiewicz PD (2005) Synaptic mechanisms that shape visual signaling at the inner retina. Prog Brain Res 147:205-218. 
Luo X, Ghosh KK, Martin PR, Grunert U (1999) Analysis of two types of cone bipolar cells in the retina of a new world monkey, the marmoset, Callithrix jacchus. Vis Neurosci 16:707-719.

Mangel SC (1991) Analysis of the horizontal cell contribution to the receptive field surround of ganglion cells in the rabbit retina. J Physiol (Lond) 442:211-234.

Margolis DJ, Detwiler PB (2007) Different mechanisms generate maintained activity in on and off retinal ganglion cells. J Neurosci 27:5994-6005.

Massey SC, Mills SL (1996) A calbindin-immunoreactive cone bipolar cell type in the rabbit retina. J Comp Neurol 366:15-33.

McLellan JS, Marcos S, Prieto PM, Burns SA (2002) Imperfect optics may be the eye's defence against chromatic blur. Nature 417:174-176.

McMahon MJ, Packer OS, Dacey DM (2004) The classical receptive field surround of primate parasol ganglion cells is mediated primarily by a non-gabaergic pathway. J Neurosci 24:3736-3745.

Nirenberg S, Meister M (1997) The light response of retinal ganglion cells is truncated by a displaced amacrine circuit. Neuron 18:637-650.

Packer OS, Dacey DM (2002) Receptive field structure of h1 horizontal cells in macaque monkey retina. J Vis 2:272-292.

Perry VH, Cowey A (1985) The ganglion cell and cone distributions in the monkey's retina: implications for central magnification factors. Vision Res 25:1795-1810.

Petrusca D, Grivich M, Sher A, Field GD, Gauthier J, Greschner M, Shlens J, Chichilnisky EJ, Litke AM (2007) Identification and characterization of a y-like primate retinal ganglion cell type. J Neurosci 27:11019-11027.

Reid RC, Shapley RM (2002) Space and time maps of cone photoreceptor signals in macaque lateral geniculate nucleus. J Neurosci 22:6158-6175.

Rieke F, Warland D, Steveninck RR, Bialek W (1997) Spikes: exploring the neural code. Cambridge, MA: MIT.

Rodieck RW (1991) The density recovery profile: a method for the analysis of points in the plane applicable to retinal studies. Vis Neurosci 6:95-111.

Rodieck RW (1998) The first steps in seeing. Sunderland, MA: Sinauer.

Roerdink JBTM, Meijster A (2001) The watershed transform: definitions, algorithms and parallelization strategies. Fundamenta Informaticae 41:187-228.

Schein S, Sterling P, Ngo IT, Huang TM, Herr S (2004) Evidence that each s cone in macaque fovea drives one narrow-field and several wide-field blue-yellow ganglion cells. J Neurosci 24:8366-8378.

Schnapf JL, Kraft TW, Nunn BJ, Baylor DA (1988) Spectral sensitivity of primate photoreceptors. Vis Neurosci 1:255-261.

Schnapf JL, Nunn BJ, Meister M, Baylor DA (1990) Visual transduction in cones of the monkey Macaca fascicularis. J Physiol (Lond) 427:681-713.
Segev R, Puchalla J, Berry II MJ (2006) Functional organization of ganglion cells in the salamander retina. J Neurophysiol 95:2277-2292.

Sernagor E, Eglen SJ, Wong RO (2001) Development of retinal ganglion cell structure and function. Prog Retin Eye Res 20:139-174.

Shapiro MB, Schein S, Monasterio FM (1985) Regularity and structure of the spatial pattern of blue cones of macaque retina. J Am Stat Assoc $80: 803-812$.

Silveira LC, Perry VH (1991) The topography of magnocellular projecting ganglion cells ( $\mathrm{m}$-ganglion cells) in the primate retina. Neuroscience 40:217-237.

Slaughter MM, Miller RF (1981) 2-Amino-4-phosphonobutyric acid: a new pharmacological tool for retina research. Science 211:182-185.

Vaney DI, Gynther IC, Young HM (1991) Rod-signal interneurons in the rabbit retina: 2. aii amacrine cells. J Comp Neurol 310:154-169.

Wandell BA (1995) Foundations of vision. Sunderland, MA: Sinauer.

Wassle H, Boycott BB, Illing RB (1981) Morphology and mosaic of on-and off-beta cells in the cat retina and some functional considerations. Proc R Soc Lond B Biol Sci 212:177-195.

Wassle H, Dacey DM, Haun T, Haverkamp S, Grunert U, Boycott BB (2000) The mosaic of horizontal cells in the macaque monkey retina: with a comment on biplexiform ganglion cells. Vis Neurosci 17:591-608.

Wassle H, Peichl L, Boycott BB (1981) Dendritic territories of cat retinal ganglion cells. Nature 292:344-345.

Wassle H, Riemann HJ (1978) The mosaic of nerve cells in the mammalian retina. Proc R Soc Lond B Biol Sci 200:441-461.

Werblin FS, Dowling JE (1969) Organization of the retina of the mudpuppy, necturus maculosus. ii. intracellular recording. J Neurophysiol 32:339-355.

Wiesel TN, Hubel DH (1966) Spatial and chromatic interactions in the lateral geniculate body of the rhesus monkey. J Neurophysiol 29:1115-1156.

Yamada ES, Bordt AS, Marshak DW (2005) Wide-field ganglion cells in macaque retinas. Vis Neurosci 22:383-393.

Young HM, Vaney DI (1991) Rod-signal interneurons in the rabbit retina: 1. Rod bipolar cells. J Comp Neurol 310:139-153.

Zaghloul KA, Boahen K, Demb JB (2003) Different circuits for on and off retinal ganglion cells cause different contrast sensitivities. J Neurosci 23:2645-2654.

Zaghloul KA, Manookin MB, Borghuis BG, Boahen K, Demb JB (2007) Functional circuitry for peripheral suppression in mammalian y-type retinal ganglion cells. J Neurophysiol 97:4327-4340.

Zhan XJ, Troy JB (2000) Modeling cat retinal beta-cell arrays. Vis Neurosci 17:23-39.

Zhang Y, Reid RC (2005) Single-neuron responses and neuronal decisions in a vernier task. Proc Natl Acad Sci USA 102:3507-3512. 